\title{
Manuel Gálvez y su trilogía de la guerra uruguaya
}

1. Los caminos de la muerte (1928)

2. Humaitá (1929)

3. Jornadas de agonia (1929)

M anuel Gálvez, nacido en 1882, es uno de los más prolíficos y 11 discutidos escritores de la Argentina en la primera mitad del siglo $\mathrm{xx}$. En su fecunda carrera literaria ha probado su fuerza $y$ talento, en una pluralidad de campos que no deja de asombrar y hasta confundir al más versado y ducho de los críticos. Muy joven aún fundó la revista Ideas, en la que empezó a desplegar su habilidad como escritor. Ha cultivado desde entonces la poesía, el drama, la biografía, la novela, $y$ ha publicado más de treinta obras, sin contar abundantes ensayos de crítica, historia y sociología.

Su obra de novelista es copiosa y varia, y toda ella acusa un hábil dominio del género. Así se expresó Cansinos Assens, allá por 1928, en la prensa de Madrid, precisamente a raíz de la publicación de Los caminos de la muerte: "La proceridad del genio novelístico de Manuel Gálvez es ya tan notoria en su continente y en el nuestro, $y$ ha sido proclamada por tantos críticos de voz internacional, que excusa la tarea de la comprobación... Georg Brandés, Romain Rolland, Valery Larbaud, Upton Sinclair, Israel Zangwill, Unamuno y Heinrich Mann, al reconocer los méritos novelísticos de Gálvez y señalar con perspicacia del crítico y el artista las partes más vitales de su obra, nos han condenado a no ser otra cosa que eco 
de sus voces ilustres, $y$, en todo caso, corroboradores humildes y superfluos de su testimonio decisivo".

La novela argentina cuenta con su tradición propia. La Amalia de José Mármol y el Facundo de Sarmiento encierran el germen de lo que distinguirá la novela argentina, hasta hoy: una combinación de lo realista y lo romántico, de lo sentimental y lo brutal. Las dos ramificaciones fundamentales de la novela argentina son, por un lado, la pampa y las costumbres provincianas; y, por otro, Buenos Aires, sus barrios, su vida social, su política y su corrupción. En el primer aspecto descuellan Roberto J. Payró, Benito Lynch, Güiraldes, Larreta y otros; en el segundo sobresalen, entre otros, Eugenio Cambaceres y Julián Martel. Sin embargo, entre los escritores argentinos, ninguno ha logrado lo que Gálvez: abarcar en su obra los múltiples aspectos de la vida argentina. En La maestra normal (1914) describe con honda intensidad las costumbres de provincia; en $L a$ sumbra del convento (1917), el ambiente católico de Córdoba; en La pampa y su pasión (1926), los medios del mundo hípico; en El mal metafísico (1916), las inquietudes culturales del literato bohemio; en La tragedia de un hombre fuerte (1922), el antagonismo que divide los espíritus argentinos: el espiritualismo contemplativo y semifatalista de la provincia, contra el pragmatismo y el incesante progreso de las ciudades.

Dice Torres Ríoseco que "Manuel Gálvez parece encontrar su verdadero camino en la novela histórica pura: Los caminos de la muerte; Humaitá y Jornadas de agonía". ${ }^{2} \mathrm{Y}$ añade, a renglón seguido: “... en estas tres novelas de las guerras del Paraguay, Gálvez ha puesto toda su pasión de poeta y de romántico, y como todas son novelas de acción, es decir, la novela en su forma más sencilla, el lector galopa por estas páginas sin detenerse ante los detalles que pudieran retardar el movimiento."

Un dato curioso sobre esta trilogia es precisamente la polaridad crítica que ha despertado tanto en América como en Europa. Algunos críticos la han atacado furiosamente; algunos, hasta llegar a decir que lo único bueno que tiene es que ofrece a la juventud literata argentina un ejemplo de lo que no debe hacer. ${ }^{3}$ Otros, sin embargo, han pronunciado los más encomiosos y laudatorios juicios. 
Las tres novelas han circulado profusamente, no sólo en la Argentina y en la América Hispana, sino que han sido traducidas a varias lenguas. ${ }^{4}$

En el diario La Tribuna, de Buenos Aires, el 12 de enero de 1947, apareció una entrevista que el periodista Juan Carlos Moreno le hizo a Manuel Gálvez. Respondiendo a la pregunta "¿Qué fin persigue usted al escribir?", el escritor argentino contestó: "Yo escribo por pasión literaria, por amor al trabajo, por vocación... Tal vez ningún escritor argentino ha tenido en Europa los éxitos que he tenido yo. Basta un ejemplo: en 1939, el gobierno de Francia (según telegrama que publicó La Prensa) dispuso que los aspirantes al ingreso en la Escuela Naval, debían conocer, para el examen, veinte libros, entre los cuales, junto a obras de Racine, Balzac, Blake, Maugham, Madariaga, Thomas Mann, y otros, figuraba mi libro Los caminos de la muerte, años atrás traducido y editado por la Nouvelle Revue Française."

Compárese el párrafo anterior, o el juicio de Cansinos Assens transcrito al comienzo de este trabajo, con las palabras de José Bianco (h), en las páginas de la venerable revista argentina Nosotros, a propósito de la publicación del primer tomo de la trilogía: "En esta novela tan poco afortunada, todos los personajes son episódicos y carentes de interés ... todo es arbitrario y convencional. Gálvez r elata los hechos, no como novelista sino como gacetillero policial... la novela no puede ser más confusa, más aburrida, menos 'novela', en una palabra, de lo que es..."

Conviene, pues, que ante la empresa de una apreciación crítica de esta obra, tomemos un curso objetivo, antes de añadir algo más sobre los encontrados juicios que la misma ha provocado.

Contemplemos el marco histórico de la trilogía. Allá para 1860 Francisco Solano López sucede a su padre, en el gobierno del Paraguay. Surgen inmediatamente problemas con la vecina nación del Brasil. En 1865 Mitre rehusa la petición que le hace López, para que le permita cruzar Corrientes e invadir la provincia brasileña de Río Grande. Dos meses más tarde, cinco barcos de la flota del Paraguay llegan a las cercanías de Corrientes, se adueñan de dos barcos de guerra argentinos e invaden la ciudad. Este acto de agresión 
significa sólo una cosa: estado de guerra entre la Argentina y el Paraguay. En mayo de 1865, Brasil, Uruguay y la Argentina firman el tratado de la Triple Alianza, cuyo fin primordial es derrocar a López. "Pueden mencionarse, como causas principales de esta guerra : la actitud celosa y a la vez retadora de López para con sus vecinos brasileños y las quejas que en esa rivalidad tuvieron su origen; la disposición del dictador paraguayo a entremeterse en los conflictos civiles del pequeño Paraguay; y por fin su ensueño de que podría hacer el papel de un Napoleón americano." ${ }^{8}$

La guerra termina, después de cinco años de luchas heroicas, saliendo vencedores los países aliados. La guerra toca a su fin, con la muerte de Solano López quien, batiéndose en retirada, recibe un lanzazo en el vientre y se arrastra hasta las márgenes de una barranca donde, perseguido por los soldados aliados, rehusa rendirse, y cae por fin, de un certero balazo al corazón que le dispara un soldado brasileño.

\section{Los caminos de la muerte.}

La acción comienza durante las Pascuas de 1865, en Buenos Aires. Se sabe que las fuerzas de López han tomado a Corrientes, el 13 de abril. Preparación total para la guerra. Demostraciones populares y ansias de limpiar con sangre el manchado honor nacional. Descripción magistral de personas, lugares y situaciones. Los Guevara y los Carvajal: típicas familias porteñas; la Buenos Aires semiprovinciana de mediados de siglo diecinueve. Lírica descripción de Corrientes (una de las mejor logradas en toda la trilogía), y allí Rudecindo Taboada, el caudillo gaucho, y su mujer Braulia. Gálvez, entrelazando el arrebato de la pasión y los celos, en el paño sangriento de la temible campaña, combina lo brutal de la guerra con los dramas sutiles que se suscitan en las relaciones íntimas del hombre. Cae la uruguaya en poder de los aliados, y comienza una marcha dolorosa a través de pantanos y selvas, rumbo a Corrientes. Cerca de esta ciudad, Antonio Guevara muere dejando viuda a su virgen esposa Dorila Carvajal. Aparece el general Mitre quien, con serenidad y firmeza, ordena a los ejércitos aliados que crucen al suelo 
paraguayo protegidos por la artillería naval del Brasil estacionada en la aguas caudalosas del Paraná.

\section{Humaitá.}

Es el año 1866. El tirano López se encastilla en la fortaleza Humaitá, situada en la confluencia de los ríos Paraguay y Paraná, y se prepara para la lucha con los ejércitos aliados. De nuevo descripción minuciosa de personajes, incidentes y paisajes. De nuevo la pesadez y el terror velado de la batalla inminente. Desfilan ante el lector varios tipos de uno y otro bandos. En el bando aliado, Evaristo Sauce, enamorado de una guapa enfermera brasileña; luego, la familia paraguaya Cienfuegos, tres de cuyos hijos sirven al tirano, siendo el de más relieve en la historia Eusebio, estudiante de teología, quien en lo hondo de su corazón odia al dictador, aunque mantiene viva su lealtad hacia el Paraguay. Historial de batallas; entre ellas, la de Curuzú - horrible carniceria. Y luego, la memorable entrevista entre el general Mitre y el tirano López, en la cual los dos grandes caudillos no logran ponerse de acuerdo. Según Mitre, sólo una cosa puede traer la paz: la caída de López y su sistema; pero López prefiere morir, antes que abdicar.

Los aliados se ven forzados a atacar a Curupayti, cerca de Humaitá, y son bochornosamente derrotados. Una epidemia de cólera se desata en ambos compamentos. De nuevo, en el tapiz macabro de la guerra, otra tragedia, en tono menor, que surge al perder la vida Evaristo Sauce, a causa de los celos del asesino Andrade, quien trunca los amores de aquél con la hermosa viudita brasileña Lucila Andrade.

Idolatría supersticiosa del populacho paraguayo, por el dictador. $\mathrm{Y}$ surge otra figura gigante $\mathrm{y}$ enigmática en la trama: el Padre Maiz, ex profesor de Eusebio, quien al principio está contra López y a la larga se convierte en el más fanático de sus secuaces.

Lentamente el ejército aliado empieza a acorralar las fuerzas paraguayas, y ya para febrero de 1868 aparecen barcos del Brasil en Asunción. López, en un movimiento defensivo y táctico, se retira hacia el norte, dejando cerca de tres mil hombres en la imponente fortaleza de Humaitá. 


\section{Jornadas de agonía.}

Ultimas etapas de la guerra. El nombre de esta parte no puede ser más apropiado. López, su querida europea Elisa Lynch, su estado mayor y el resto de su ejército, famélico y desorganizado, se encuentran en sus nuevas posiciones al norte. La marcha ha sido forzada, bajo la miseria. El dictador va perdiendo poco a poco su equilibrio mental. Bebe sin tasa y la palabra 'traición' repercute constantemente en su interior, como campanadas que anuncian una muerte cercana. El miedo empieza a apoderarse de sus facultades, y en un arranque de soberbia manda a fusilar a dos mil paragtuayos (incluyendo hombres y mujeres), acusándoles sumariamente de traición. La desesperación obliga al tirano a reclutar hasta los niños de escuela. De nuevo la pincelada sensitiva y patética, encarnada esta vez en la familia Rosales, la cual (por sospecha de traición) se ve forzada a emprender una peregrinación sin rumbo, por entre selvas, estepas, ríos y pantanos, escoltada por una guardia brutal. $\mathrm{Y}$ a la vez, una nota de pálida alegría entre el caos: Damasceno Fragoso, capitán brasileño, después de buscar en vano a su esposa Joaninha (quien había quedado en Asunción al estallar la guerra), la encuentra en medio de la más abyecta miseria y desolación.

Los argentinos y brasileños asaltan el campamento de Caraguatá, y se cierra la guerra con la victoria de los aliados en Peribuey. López cae muerto a lanza y fusil, y la única persona que lo llora es su propia madre, a la cual, en su furia demente, días antes había también condenado por traidora.

Conviene en este punto hacer un alto, para señalar algunas ideas en torno a la novela histórica. Cuando Walter Scott creó este tipo de literatura, aportó al campo de las letras, no sólo una contribución valiosísima, desde el punto de vista estético, sino que añadió al mundo de la crítica literaria un nuevo género que por su propio carácter habría de traer interminables polémicas. La novela histórica se inspira en el pasado, tratando de reproducir los ambientes dentro de un nàarco de fidelidad. Siendo el asunto de esta novela 
algún suceso o tema histórico, el autor se ve compelido a embellecer, idealizar, o dar color a dichos actos o personajes históricos teniendo en cuenta, sobre todo, el respeto de sus caracteristicas fundamentales, absteniéndose de contradecir o desfigurar. Esta inevitable limitación y “... en particular, el pleno conocimiento del espíritu, circunstancias ambientales, costumbres y sentimientos de la época, que se trata de revivir, implica la grande y verdadera dificultad de este importantísimo género novelesco". ${ }^{7}$

No nos sorprenden, por esto, las siguientes palabras de Amado Alonso: “. . a a pesar del éxito tan fulminante y tan universal, la novela histórica está en crisis desde su nacimiento". ${ }^{8}$ La dificultad y la constante crisis de la novela histórica consiste precisamente en el equilibrio que está presente entre lo histórico y lo poético; equilibrio que, por bien que el escritor lo realice, siempre hallará críticos que formulen serias interrogaciones. Recordamos el caso de aquello que nos contaba Heinrich Meyer $^{9}$ al referir que Leopold von Ranke (auténtico historiador objetivo) quedó profundamente disgustado al leer una de las obras de Walter Scott, por haber hallado falseamiento de la verdad y deformaciones que a su juicio eran innecesarias porque, según él, la realidad era más pintoresca que aquella ficción.

Amado Alonso, lanzando luz sobre el asunto, dice: "La historia quiere explicarse los sucesos observándolos criticamente desde fuera y cosiéndolos con un hilo de comprensión intelectual; la poesía quiere vivirlos desde dentro, creando en sus actores una vida auténticamente valedera como vida, gracias al acto poético de instalarse el autor en cada uno de sus personajes, identificándose alternativamente con ellos, viviéndolos intensa y profundamente con una conciencia lúcida que le permite sentir y expresar con nitidez, presentativa y no explicativamente, hasta las más pequeñas raicillas de cada movimiento." 10

Añade, sin embargo, el distinguido crítico que cuando la novela histórica trata de un hecho o tema reciente, "el conflicto entre la invención y la información no existe". ${ }^{11}$ Aquí no podemos estar de acuerdo con la opinión del distinguido crítico. A nuestro juicio, tan pronto como se pretende hacer literatura sobre algo que ha sucedido (llámese 'ayer' o llámese el 'imperio babilónieo', la época en que ocurriera), inmediatamente se halla el escritor frente al conflic- 
to inevitable de la intuición contra el historicismo puro. Entre los novelistas que cita Amado Alonso para corroborar su tesis, están: Galdós con sus Episodios nacionales, Pereda (Pedro Sánchez), Valle Inclán (La guerra carlista), Unamuno (Paz en la guerra), Lugones (La guerra gaucha), Payró (El capitán Vergara), y Manuel Gálvez con su trilogia: Los caminos de la muerte, Humaitá y Jornadas de agonía.

Abundando en el tema apuntado por Amado Alonso, José Bianco (h.) -a quien ya hemos citado previamente- nos dice: "por lo general, salvo excepciones, el autor se ve obligado a sacrificar una de las dos cosas: novela o historia; vale decir, a hacer historia lisa y sencillamente, rodeándola de cierto artificio literario, a manera de los clásicos... o a escribir una novela apoyándose incidentalmente en la historia, utilizando algunos datos que nos brinda la historia". ${ }^{12}$ Y sigue el crítico de Nosotros, a continuación: "Manuel Gálvez, en su intento de llevar a cabo plenamente ambas cosas no ha realizado ninguna". $\mathrm{Y}$ esto es dicho a propósito de la publicación de Los caminos de la muerte. Siguiendo esta misma línea de pensamiento, el crítico Ramón Doll, en la misma revista Nosotros se expresó del siguiente modo al publicarse Humaitá : "Gálvez se ha sustraído de la novela y planea sobre ella limitándose a contar con la concisa esquematización de un 'announceur' de radio que da noticias de un 'match'." 13

En una conferencia que sustentó Henry Alfred Holmes, en el Instituto de las Españas, de Nueva York, encontramos las siguientes frases, en la conclusión: "Si no hubiese otro motivo de formular un juicio favorable, el mero hecho de que Gálvez, conocido y apreciado en tres continentes, haya escrito una obra que concierne a los habitantes de cuatro repúblicas suramericanas y cuya acción entera tiende a revelar los aspectos horribles de la tiranía, vale decir, de la guerra, repito que esto sólo pustificaría la aparición de esta trilogia precisamente en estos tiempos." 14

$\mathrm{Y}$ siguen los choques de opiniones. El conflicto se resuelve una y mil veces en. la fórmula de lo intuitivo-poético y lo concreto-histórico. En nuestro carácter de observadores laicos, y ante una vista 
total de la obra - que es lo que a la larga cuenta y perdura-, expondremos, para terminar, nuestro juicio general acerca de la discutida trilogía.

Empecemos por lo más débil. Gálvez tiene el defecto de la exposición minuciosa llegando a veces al extremo de lo cursi y caricaturesco. (Aquí recordamos la atinada definición que nos dió un día Mariano Picón Salas, sobre lo cursi: "Lo cursi", dijo el maestro, "es la frustración de lo sublime"). Hay mucho detalle superfluo y cansado, en algunas de las descripciones; de tal modo que el lector, a veces fatigado y confundido, pierde el hilo de la narración, y en su mente rebotan menudencias que oscurecen a ratos la hebra luminosa que une la trama. Gálvez ha sido muy censurado por su estilo poco acabado ; crítica que también ha recibido otro prolifico escritor, el español Pío Baroja. En muchos instantes la trilogía exhibe falta de gracia; abunda en lugares comunes, y a veces hasta detalles de mal gusto. En el léxico de estas tres novelas hay una mezcla profusa e interesante del más pintoresco criollismo y los más rebuscados giros de la lengua castellana.

Se acusa a Gálvez de no dar a conocer el proceso psicológico que mueve a distintos caracteres básicos de la obra. Un ejemplo que recordamos es el de Taboada al asesinar a su mujer Braulia, en Los caminos de la muerte. El lector ignora los móviles subjetivos de la tragedia y para el caso lo mismo hubiera dado que Braulia le asestase la puñalada al marido cuando éste dormía.

Sostenemos, sin embargo, que esta obra de Gálvez posee, en conjunto, méritos indiscutibles. Refiriéndose al fondo y la forma del popular escritor argentino, dice Tristán Valdaspe: "Observador sagaz, se muestra más atento al fondo que a la forma, olvidando a veces, como el mismo Pereda, en su afán de realismo y exactitud, que el arte es selección, simplificación, sobriedad, y que el artista manifiesta concentrando. Con todo, si la forma puede parecer a ratos desaliñada y difusa, hay en sus novelas, como en los escritos de Sarmiento, tanta vida, $y$ tal poder de evocación que suplen con creces la carencia de los primores del estilo." 15

La trilogía es obra de intenso dramatismo, en la cual, pasando los personajes por el rigor de la campaña, se precipitan, en los dos bandos, hacia la realización de un ideal. La obra, en su conjunto, 
posee acción, dinamismo y movimiento, a pesar de estancarse de vez en cuando en consideraciones superfluas.

Gálvez no desfigura la historia; se ciñe a ella con inusitada lealtad, la embellece, y se lanza a su aventura creadora. Es imparcial en su exposición de sucesos, vivísimo en sus descripciones, y muy humano ante la tragedia. El novelista ha sido feliz en su presentación de López, quien, como centro de una órbita inmensa, atrae hacia su persona todos los acontecimientos. El dictador paraguayo es el blanco de adulaciones, aclamaciones, devoción, conspiraciones, odio, desprecio; es el blanco final de la misma muerte, en esa orgía de sangre que es la guerra del Paraguay.

Por último, Gálvez nos deja ver en su trilogía su gran interés por la vida social de los pueblos. Esto lo ha heredado, seguramente, de su preparación académica en las aulas argentinas, donde llegó a preocuparse hondamente por los problemas sociales de su país. Según apunta el distinguido crítico norteamericano J. R. Spell, "lo que distingue Las escenas de la guerra del Paraguay es el caudal de material que hace de la obra un documento viviente de la vida social de la época". 16 De ahí que, como punto final de estas consideraciones, hagamos hincapié en que Gálvez, antes que escritor es hombre, "hombre de carne y hueso", como diría Unamuno, que vive $y$ siente las pulsaciones de la humanidad que sufre y vive presa de constantes inquietudes.

\section{Guillermo Cotro-ThorNer, University of Texas.}

\section{NOTAS}

1 CANSINOS Assens, R. "Sobre 'Los caminos de la muerte' de Manuel Gálvez", La Libertad, (Madrid), 4 de agosto de 1928.

2 Torres Rfoseco, A. Grandes Novelistas de la Amética Hispana (parte II), University of California Press, 1943, p. 150.

3 BIANCO (h.), J. "Letras argentinas: "Los caminos de la muerte?", Nosotros, (Buenos Aires), año XXII, tomo LXI, julio, 1928, p. 105.

4 Las tres novelas han sido traducidas al francés: Jornadas de agonía también al portugués. La trilogía acaba de aparecer en alemán, en un gran tomo de 820 páginas, bajo el título de López, editado en Viena por Paul Zsolnay. 
5 BIANCO (h.), J. Ibid., p. 105.

6 Holmes, Henry Alfred. "Una trilogía de Manuel Gálvez", Revista Hispánica Moderna, (Nueva York), año III, núm. 3: abril, 1937, p. 202.

7 Gayol Fernandez, Manuel. Teotia Literatia-Nueva Preceptiva, Habana, Cultural, S. A., 1939, p. 504.

8 Alonso, Amado. Ensayo sobre la novela histórica. Instituto de Filologia, Universidad de Buenos Aires, 1942, p. 73.

9 MEYER, Heinrich. "Ranke the Historian”, Philosophia, vol. I, 1936, p. 233 .

10 Alonso, Amado. Ibid., p. 18.

11 Alonso, Amado. Ibid., p. 145.

12 Bianco (h.), J. Ibid., p. 100.

13 Doll, Ramón. "Humaitá", Nosotros, (Buenos Aires), año XXIII, tomo LXIV, abril, 1929, p. 274.

14 Holmes, Alfred Henry. Ibid., p. 211.

15 VAldAsPE, Tristán. Historia de la Literatura Hispanoamericana, Buenos Aires, Editorial F. V. D., 1943, p. 304.

16 SPELL, J. R. Contemporary Spanish American Fiction, Chapel Hill, University of North Carolina Press, 1944, p. 53. 
